\title{
Reflection Model for Soil Moisture Measurement Using Near-infrared
}

\section{Reflection Sensor}

\author{
Zhe Yin ${ }^{1,2, a}$, Wei Qin ${ }^{1,2, b}$, Changqing Zuo, ${ }^{1,2, \mathrm{c}}$, Nan Yan ${ }^{1,2, \mathrm{~d}}$, Bai $\mathrm{Li}^{1,2, \mathrm{e}}$, Qiankun \\ Guo $^{1,2, f}$ Zhijie Shan ${ }^{1,2, g}$, Zhaoyan Wang ${ }^{1,2, h}$
}

${ }^{1}$ State Key Laboratory of Simulation and Regulation of Water Cycle in River Basin, China Institute of Water Resources and Hydropower Research, Beijing 100048, China;

${ }^{2}$ Research Center on Soil and Water Conservation of the Ministry of Water Resources, China Institute of Water Resources and Hydropower Research, Beijing 100048, China;

ayinzhe-2002@163.com, binwei_office@sina.com, 'czuochq@sina.com, ${ }^{\mathrm{d}}$ yannan8521@sina.com, elbyn1986@hotmail.com, 'guoqiankun@iwhr.com ${ }^{\mathrm{g}}$ 26431802@qq.com, h306039189@qq.com,

Keywords: Reflection, Model, Near-infrared, Soil moisture

Abstract. Surface soil moisture is a significant parameter in environmental systems. A new sensor capable of estimating surface soil moisture from reflection data is presented, called near-infrared reflection sensor. Relative reflectance method is used for prediction model development. The present study investigated the reflection variations in four soil samples with a wide range of soil properties. The results showed that quadratic models were constructed between relative reflectance and soil moisture with $\mathrm{R}^{2}$ of $0.902,0.865,0.955$, and 0.953 . The $\mathrm{R}^{2}$ of all combined soils model is 0.886. Compared with individual quadratic models for each soil sample, all combined soils quadratic model generated prediction accuracy with values of root mean square error ( $R M S E=$ $2.43 \%, 3.34 \%, 5.21 \%$ and $2.99 \%$ ). Soil moisture estimation is largely improved when the quadratic model are developed individually on each soil type except for the Soil 4, compared with all combined soils model. Individual quadratic model yielded performances very similar to the individual linear relationship. Therefore, it is feasible to construct a single quadratic model to minimize that factor effecting on reflection. The most important meaning of this study is that surface soil moisture can be rapidly and accurately measured by near-infrared reflection sensor. In the future, the prediction models can therefore provide quick assessment of surface soil moisture directly in the field.

\section{Introduction}

It has been known for a long time that soil moisture is an important control on plant growth and land management, and also has a major impact on soil surface temperature, soil erosion and aeolian sediment transport ${ }^{[1,2]}$. Near-infrared reflection measurement, as a powerful diagnostic tool, has been utilized in many disciplines such as food industries ${ }^{[3]}$, precision agriculture ${ }^{[4]}$ and pharmaceutics. Meanwhile, its potential has also been recognized for soil moisture measurement, and many researchers have investigated the soil moisture reflection using near-infrared spectroscopy. For soil samples, near-infrared reflection spectra are directly influenced by the vibration in $\mathrm{C}-\mathrm{H}, \mathrm{O}-\mathrm{H}, \mathrm{N}-\mathrm{H}$ chemical bond that absorb the light in the near infrared region ${ }^{[5,6]}$. The most prominent absorption of soil moisture, related to overtones and combinations of fundamental vibrations of O-H functional groups, occurs in 1450, 1940 and 2200nm wavelengths ${ }^{[7]}$. Therefore, the reflection spectra can provide the information of soil water. 
Many researchers have investigated the relationship between soil moisture and reflection, and the results indicate that a decrease in reflection with increasing the soil moisture content ${ }^{[8,9]}$. Twomey et al. attributed the reduction to a changing of refractive index, and the refractive index between soil and water is less than that between soil and air, so increases the average degree of forward scattering. As a consequence, that increases the internal reflection of soil and results in greater probability of being absorbance ${ }^{[10]}$. But Neema et al. and Liu et al. found that the reflection reduces with increasing moisture content, after a critical point, the reflection increases with increase of soil moisture ${ }^{[11,12]}$. So, constructing different predicted model has to be taken into account, while estimating the soil moisture from reflection. Although a number of authors have studied the overall trend of reflection varying with soil moisture, a reliable model will be needed for the quantitative estimation of soil moisture. Lobell et al. generated exponential regression model using four soils, suggesting that longer wavelengths are better suited for predicting volumetric moisture content above $20 \%^{[1]}$. Whiting et al. used the Gaussian model to predict the soil moisture, reducing the root mean square error $(R M S E)^{[13]}$. Haubrock et al. introduced a new soil moisture index named the Normalized Soil Moisture Index (NSMI), and achieved linear regression model between soil moisture and NSMI at 1800 and $2119 \mathrm{~nm}$ wavelength with coefficient of determination $\left(\mathrm{R}^{2}\right)$ of $0.6^{[14]}$. At single wavelength, soil reflection on soil water content can be well described by simple exponential decay equations, but showing distinct response patterns due to variation of soil properties ${ }^{[15]}$. However, all of these studies obtain reflection data employing spectrometer, which has high cost and power consumption and not applicable for situ measurement. This paper will measure the reflection data using Light emitting diodes (LED)-based near-infrared reflection sensor, which has been developed for use as a portable soil moisture meter. The major advantages of the system are its small size, low power consumption, longer lifetime and without any further spectral filtering.

The main object of this study are: (1) Investigate the correlations between reflection and soil moisture varying from dry to saturation for four soil types; (2) Take a step towards developing the predicted model with relative reflectance method for estimating soil moisture from reflection measurements; (3) Evaluate the accuracy of predicting soil moisture content based on soil reflection measurements;

\section{Materials and methods}

\section{Soil sample and reflection measurement}

Four soil samples were collected from different locations in China. The soil properties were measured and the mechanical composition was determined using an aerometric method (Table 1). All soil samples were first air dried and passed through a $1 \mathrm{~mm}$ mesh sieve. Then the soils were packed in small, stainless steel corers with removable tops and bottoms. A piece of filter paper was placed against the bottom of the ring. The corers had the capacity of $100 \mathrm{~cm}^{3}$ (Radius $5 \mathrm{~cm}$ ). Because the light only interacting with surface soil, forming a few millimeters penetration depth in soil. For keeping soil moisture uniformity in the ring from top to bottom, a new soil moisture adjusting method was developed: (1) Put the corers filled with soil into distilled water, and the water will removed into the soil through the filter paper; (2) After the soils were saturated, all of which will be taken into porous plate extraction system that can extract water from soils under air pressure provided by high pressure air tank; (3) when a certain amount of water extracted from that system, the soils were taken out and measured the infrared reflection of soil surface, then immediately weighted the soil samples for calculating corresponding soil moisture. The soil samples were removed periodically from the pressure chamber and weighted until equilibrium was 
reached at the 15 bar suction that accepted as wilting point.

Table 1 Characters of the four soil samples

\begin{tabular}{|c|c|c|c|c|c|}
\hline \multirow{2}{*}{$\begin{array}{c}\text { Sample } \\
\text { no. }\end{array}$} & \multirow{2}{*}{ Field } & \multirow{2}{*}{$\begin{array}{c}\text { Moisture } \\
\text { content } \\
\text { range }\end{array}$} & \multicolumn{3}{|c|}{ Mechanical composition } \\
\hline & & & Sand & Silt & Clay \\
\hline & & & & $\%$ & \\
\hline Soil 1 & Changchun & $0 \sim 50.1$ & 45 & 40 & 15 \\
\hline Soil 2 & Yangling & $0 \sim 50.0$ & 23 & 48 & 29 \\
\hline Soil 3 & Yan'an & $0 \sim 52.0$ & 25 & 36 & 39 \\
\hline Soil 4 & Chongqing & $0 \sim 47.1$ & 61 & 20 & 19 \\
\hline
\end{tabular}

Soil surface reflection data at 1800 and $1940 \mathrm{~nm}$ wavelength were acquired with near-infrared reflection sensor that has been designed and used in the laboratory. The LED-based optical sensor is shown in Fig. 1. LEDs are at an incident angle of $45^{\circ}$ to normal incidence respectively. The detector is positioned vertically at a distance of $15 \mathrm{~mm}$ from the soil sample surface and six light emitting diodes (LEDs) arrange circularly around light detector.. The three LEDs (band centred at $1800 \mathrm{~nm}$ and band centred at $1940 \mathrm{~nm}$ ) sequentially are driven and the radiation from LEDs at a time is directed to soil surface. Detector receives the reflection light and is followed by a two-stage preamplifier before data acquisition by the analog to digital converter. At the same time, a large number of times the measurements were replicated over the same target to minimize the measurement uncertainty.

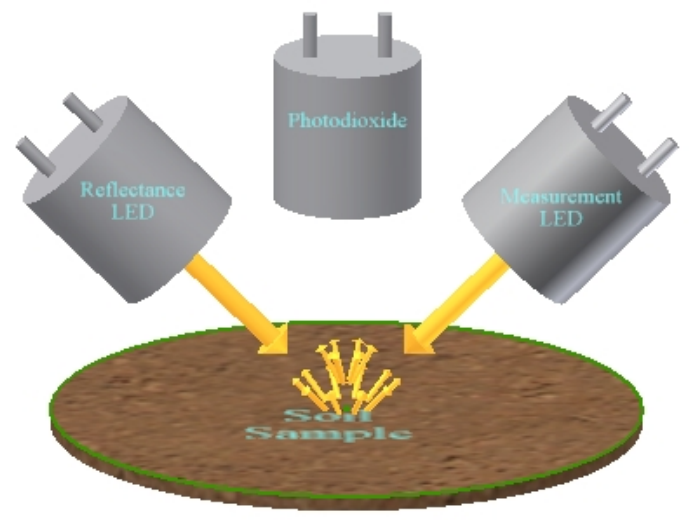

Fig. 1. LED-based optical sensor case schematic

\section{Model method}

Soil moisture estimation approaches based on reflection data have been discussed extensively in the literature ${ }^{[1,14,16,17]}$. In this study, relative reflectance approach is investigated to develop the relationships between reflection measurement and soil moisture.

\section{Relative reflectance approach}

Single absolute reflection is normalized by the reflection under dry conditions over the same soil. It is termed as relative reflectance approach and used only one wavelength, which can minimize the effect of soil type, sample geometry and surface roughness ${ }^{[12]}$.

$$
R^{\prime}=\frac{R_{\theta}}{R_{0}} * 100 \%
$$


where $R^{\prime}$ is the relative reflectance; $R_{\theta}$ is the reflection value of the wetted soil surface and $R_{0}$ is the reflection value of the dry soil surface.

\section{Results and Discussions}

\section{The relationship of soil moisture and relative reflectance}
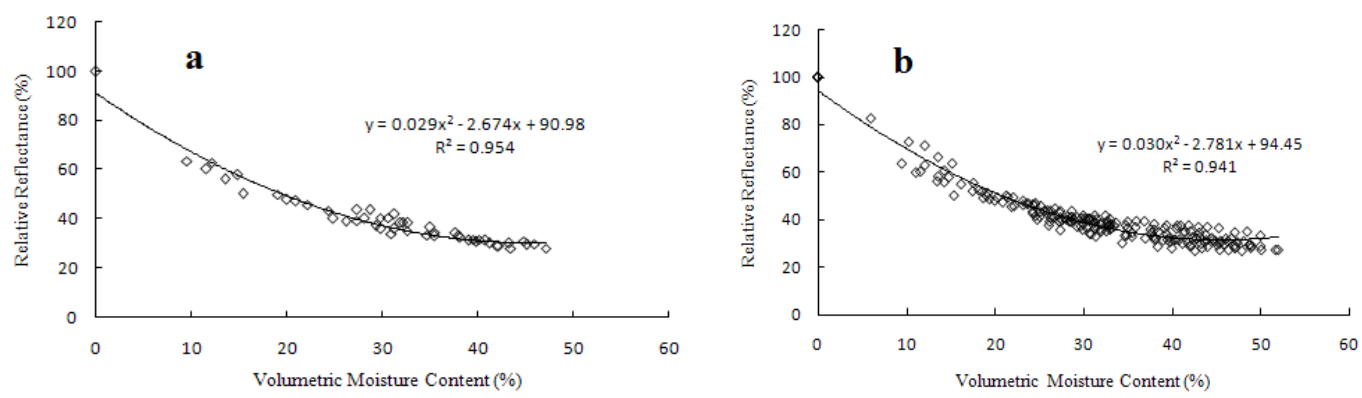

Fig. 2. Volumetric moisture content vs. relative reflectance at $1940 \mathrm{~nm}$ wavelength for: (a) individual soil 4 , (b) all combined soils.

The relative reflectance of all four soils consistently decreases from low to high moisture level, and shows similar trends. So, soil 4 is selected as an example for individual soil consider here. The quadratic model was calibrated for each soil separately, and all soils simultaneously (Fig. 2). The range of relative reflectance variation is maximal at the lower soil moisture content, but the little sensitivity of reflectance when moisture content is almost above $30 \%$. This general pattern is consistent for all four soil types. As soil moisture increases, water is first adsorbed to particles surface, and then proceeds to fill micro and macro pores ${ }^{[18]}$. So, when soil is approximate to saturation, most of particle surfaces are full of water and additional water will fill large pore which have little effect on reflection ${ }^{[1]}$. For individual soil and all soils, the quadratic function $\left(y=a x^{2}+b x+c\right)$ describes the relationship between relative reflectance and moisture content significantly well, particularly for soil 3 and soil 4 , with a high correlation efficient $\left(R^{2}>0.95\right)$, and low root mean square error (RMSE) (Table. 2). However, the regression coefficients of quadratic equations are slightly different due to variation in soil sample properties.

\section{Calibration and validation}

In order to formulate a calibration equation for each soil type, different soil moisture level composes a dataset. The dataset was divided into two groups. One group of data was used for calibration and the other for validation. The calibration data used randomly out of the dataset under soil moisture level and the prediction statistic was calculated for the remaining data. At the same time, a single prediction model is constructed using all four datasets.

The best models were defined as those which presented lower values of root mean square error and higher determination coefficient $\left(R^{2}\right)$, therefore, two statistical indices were employed to estimate the accuracy of the measured data, the determination coefficients $\left(R^{2}\right)$ and root mean square error (RMSE).

$$
R^{2}=1-\sum_{i=1}^{n}\left(\hat{\theta_{i}}-\theta_{i}\right)^{2} / \sum_{i=1}^{n}\left(\hat{\theta_{i}}-\bar{\theta}\right)^{2}
$$


RMSE $=\sqrt{\frac{1}{n} \sum_{i=1}^{n}\left(\theta_{i}-\hat{\theta_{i}}\right)^{2}}$

where $\theta_{i}$ and $\hat{\theta_{i}}$ are the measured and predicted soil moisture content respectively, $\%$; $\bar{\theta}$ is the average of the observed values, $\%$; and $n$ is the number of samples.

Table 2 Parameters of fitting relative reflectance to soil moisture for four soil samples. The models were established with individual soil (each soil) and all combined soils (all of four soils).

\begin{tabular}{|c|c|c|c|c|c|c|c|c|c|c|}
\hline \multirow{2}{*}{$\begin{array}{l}\text { Sampl } \\
\text { e no. }\end{array}$} & \multicolumn{5}{|c|}{ Individual soil } & \multicolumn{5}{|c|}{ All soils } \\
\hline & $a(c)$ & $b(d)$ & $e$ & $R^{2}$ & $\begin{array}{c}\text { RMSE }(\% \\
)\end{array}$ & $a(c)$ & $b(d)$ & $e$ & $R^{2}$ & $\begin{array}{c}\text { RMSE }(\% \\
)\end{array}$ \\
\hline Soil 1 & 0.011 & -2.116 & $\begin{array}{c}94.5 \\
2\end{array}$ & $\begin{array}{c}0.90 \\
2\end{array}$ & 2.47 & & & & & 2.43 \\
\hline Soil 2 & $\begin{array}{c}0.01 \\
4\end{array}$ & $\begin{array}{c}-2.59 \\
3\end{array}$ & 112.6 & $\begin{array}{c}0.86 \\
5\end{array}$ & 2.54 & 0.01 & -2.05 & 95.0 & 0.88 & 3.34 \\
\hline Soil 3 & $\begin{array}{c}0.01 \\
2\end{array}$ & $\begin{array}{c}-2.21 \\
2\end{array}$ & $\begin{array}{c}101 . \\
5\end{array}$ & $\begin{array}{c}0.95 \\
5\end{array}$ & 3.81 & 1 & 1 & 1 & 6 & 5.21 \\
\hline Soil 4 & $\begin{array}{c}0.01 \\
0\end{array}$ & $\begin{array}{c}-1.98 \\
8\end{array}$ & $\begin{array}{c}91.2 \\
4\end{array}$ & $\begin{array}{c}0.95 \\
3\end{array}$ & 4.29 & & & & & 2.99 \\
\hline
\end{tabular}
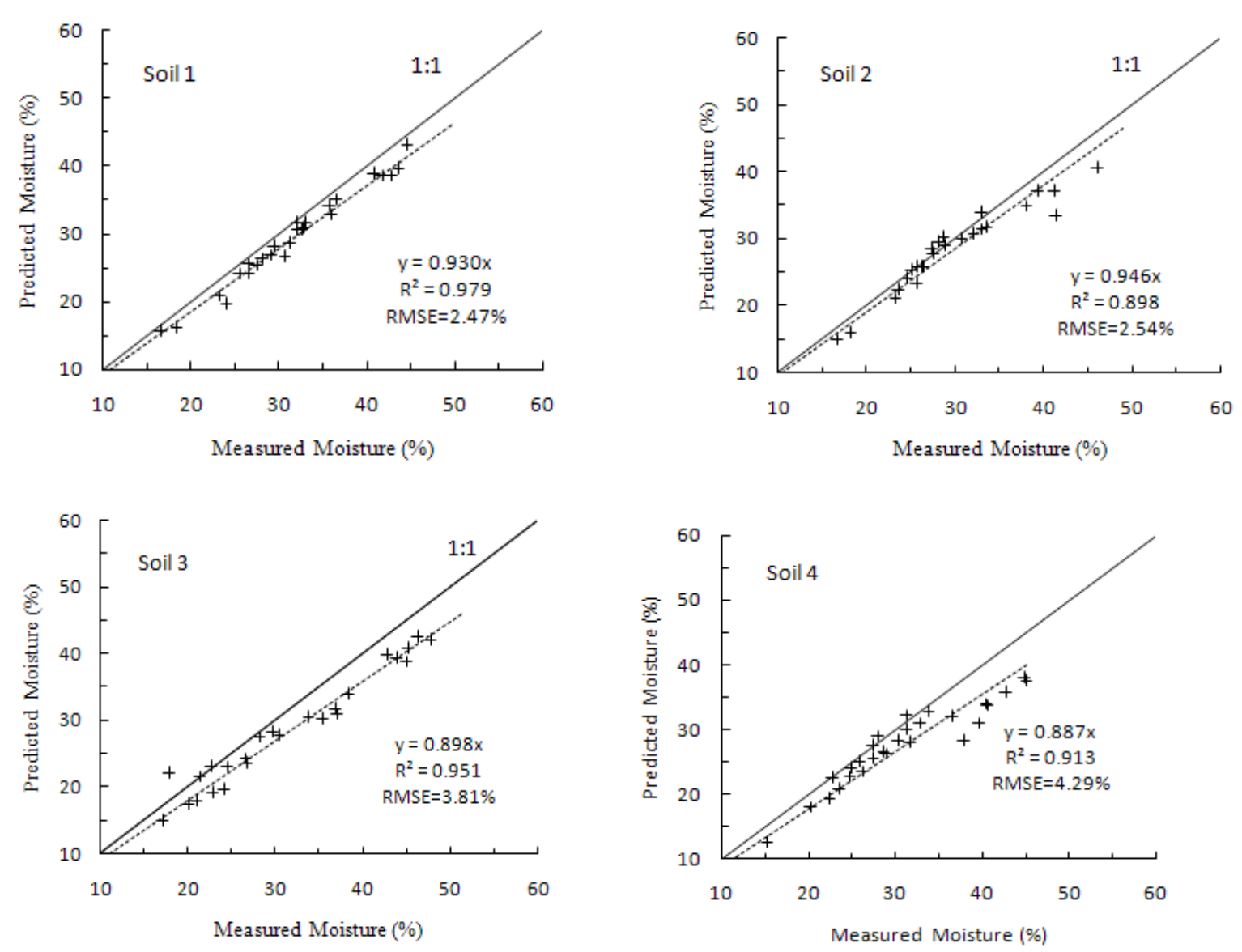

Fig. 3 Measured vs. Predicted volumetric moisture content of the four soils using individual soil quadratic model

The measured and predicted moisture content for four soil samples are compared using individual quadratic model and all combined soils quadratic model respectively in Fig. 3 and Fig. 4. For each soil type, the RMSE of individual quadratic model is $2.47 \%, 2.54 \%, 3.81 \%$ and 4.29 respectively, which indicates the quadratic model has a better prediction accuracy. The RMSE $(2.43 \%, 3.34 \%, 5.21 \%$ and $2.99 \%)$ of all soils quadratic model are approximate to that of individual 
quadratic shown in Table 2. Therefore, it is feasible to develop a single quadratic model for surface soil moisture, and relative reflectance approach can minimize the factor in the description of soil type effects on reflection. But the major disadvantage of using this method is that the fitting curve predicts high moisture contents poorly because of the relative reflectance being close to a constant when the soil moisture content reaches a certain value. It is also complicated in the field application due to the reflection value of the appropriate dry reference sample.
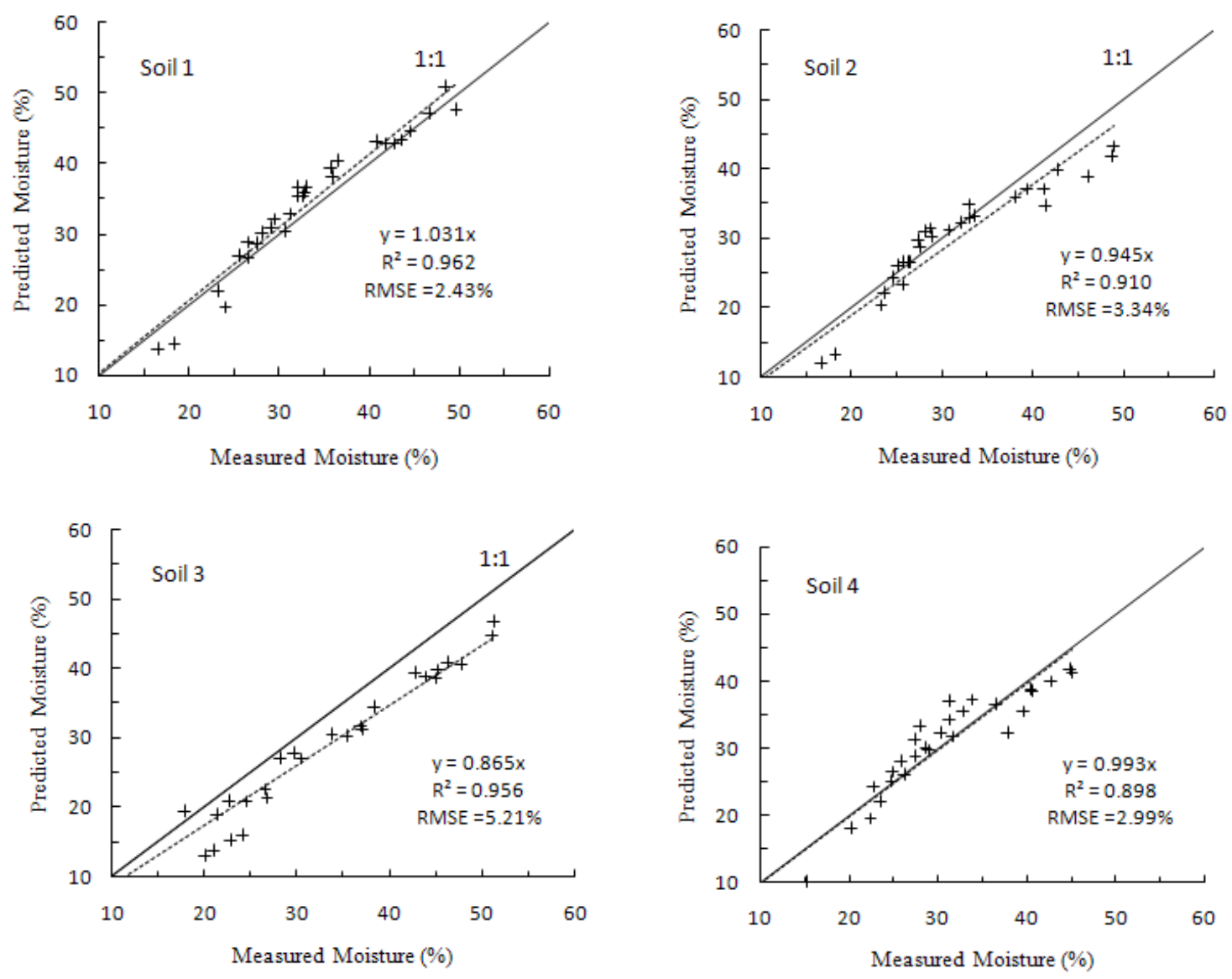

Fig. 4 Measured vs. Predicted volumetric moisture content of the four soils using all combined soils quadratic model

\section{Conclusions}

Four soil samples illustrated with near-infrared reflection sensor, and the results showed a decreasing trend of relative reflectance with increased soil moisture content. The prediction model is developed for surface soil moisture estimation, quadratic model between relative reflectance and soil moisture content. The four samples showed distinct response patterns, most likely due to the variation of soil properties including texture, soil color and organic matter content. The prediction results of individual quadratic model and all soils quadratic model are quite close. Therefore, it is easier for quadratic model to construct a single prediction.

In this study, homogenized soil samples were used for reflection measurement in the laboratory and both of the two models generated more reasonable prediction values. In future studies, the approach needs to be applied in the field, therefore, further research is necessary to test the developed modeling concepts on a larger data set covering a wider variety of soils, particularly on the applicability of the model under highly variable heterogeneous field conditions. 


\section{Acknowledgements}

This paper is based on the research supported by Natural Science Foundation of China under project No. 31200535 and by Funds for Public Industry Research Projects of the Ministry of Water Resources of China under project No. 201401025.

\section{Reference}

[1] D.B. Lobell, G.P. Asner, Moisture effects on soil reflection, Soil Science Society of America Journal, 66(2002) 722-727.

[2] G. D. Robin, Yanqi Yang, Jeff O, A.H Patrick, J.W. Ian, The effects of surface moisture on Aeolian sediment transport threshold and mass flux on a beach, Earth Surface Progresses and Landforms, 33(2008) 55-74.

[3] B.P. Hans, Analysis of water in food by near infrared spectroscopy. Food Chemistry. 82 (2003) 107-115.

[4] J.A.J. Van Vuuren, J.H. Meyer, A.S. Claassens, Potential use of near-infrared reflection monitoring in precision agriculture. Communications in Soil Science and Plant Aanlysis. 37(2006) 2171-2184.

[5] C.W. Chang, D. A. Laird, M. J. Mausbach, C. R. Hurburgn, Near-infrared reflection spectroscopyPrincipal components regression analyses of soil properties. Soil Science Society of America Journal. 65(2001) 480-490.

[6] M. Blanco, I. Villarroya, NIR spectroscopy: a rapid-response analytical tool, Trend in Analytical Chemistry, 21(2002) 240-250.

[7] S. A. Bowers, R.J. Hanks, Reflection of radiant energy from soils. Soil Science, 100(1965) 130-138.

[8] C.W. Chang, D.A. Laird, C.R. Hurburgh Jr, Influence of soil moisture on near infrared reflection spectroscopic measurement of soil properties. Soil Science. 170(2005) 244-255.

[9] B.L. David, P.A. Gregory, Moisture effects on soil reflection. Soil Science Society of America Journal, 66(2002) 722-727.

[10] S.A. Twomey, , C.F. Bohren, J.L. Mergenthaler, Reflection and albedo differences between wet and dry surfaces. Applied Optics, 25(1986) 431-437.

[11] D.L. Neema, A. Shah, A.N. Patel, A statistical optical model for light reflection and penetration through sand. International Journal of Remote Sensing, 8(1987) 1209-1217.

[12] W.D. Liu, F. Baret, X.F. Gu, Q.Z. Tong, L.F. Zheng, B. Zhang, Relating soil surface moisture to reflection. Remote Sensing of Environment, 81(2002) 238-246.

[13] M.L. Whiting, L. Li, S.L. Ustin, Predicting water content using Gaussian model on soil spectra, Remote Sensing of Environment, 89(2004) 535-552.

[14] S.N. Haubrock, S. Chabrillat, C. Lemmnitz, H. Kaufmann, Surface soil moisture quantification models from reflection data under field conditions, International Journal of Remote Sensing, 29(2008) 3-29.

[15] Y. D. Zhu, C. David, S.C. Weindorf, H. Beatrix, J. Stephanie, B. Noura, Characterizing surface soil water with field portable diffuse reflection spectroscopy. Journal of Hydrology 391(2010) 133-140.

[16] W.D. Liu, F. Baret, X.F. Gu, B. Zhang, Q.X. Tong, L.F. Zheng, Evaluation of methods for soil surface moisture estimation from reflectance data. Remote Sensing. 24(2003) 2069-2083.

[17] E. Muller, H. Decamps, Modeling soil moisture-reflectance. Remote Sensing of Environment, 76(2001) 173-180.

[18] D. Hillel, Environmental soil physics. Academic Press, San Diego, CA, 1998. 